\title{
Topological optimization of the rotors of permanent magnet synchronous motors
}

\author{
Alfred Safin ${ }^{1, *}$, and Timur Petrov ${ }^{1}$ \\ ${ }^{1}$ Kazan State Power Engineering University, Kazan, Russia
}

\begin{abstract}
Permanent magnet synchronous motors are increasingly used in the oil industry. These motors need to be made more energy efficient. To do this, it is necessary to optimize the rotor of a synchronous motor by changing the design through topological optimization. Designing an electrical machine as a heuristic process does not guarantee finding the best solution. Methods are needed that complement the experience and intuition of the designer to find the optimal (rational) solution. Topological optimization is currently performed using the finite element method to reduce mass and improve the stiffness of structures. The proposed method allows you to transfer topological optimization to electromagnetic processes in permanent magnet synchronous motors to determine the direction of magnetization and the size of permanent magnets, for a given mass-dimensional parameters. Optimization of the rotor of a serial permanent magnet motor based on a genetic algorithm is proposed. A new topology of the rotor of the motor was calculated and an increase in the torque was obtained by $18.2 \%$, which indicates that topological optimization is promising for synchronous motors with permanent magnets.
\end{abstract}

\section{Introduction}

Permanent magnet synchronous motors (PMSM) as part of a sucker rod pumping unit during oil production are distinguished by the fact that instead of an excitation winding on the rotor, they have permanent magnets that create an exciting magnetic flux. The stator of permanent magnet synchronous machines is similar to the stator of an induction motor (IM) and has a three-phase winding [6].

The use of PMSM instead of asynchronous motors to drive pumping units will improve the energy efficiency of oil production.

Permanent magnets in a synchronous machine are used to create a constant magnetic flux. As a result of the interaction of the constant magnetic flux with the stator field, a torque is generated. Consequently, the energy, weight, size and dynamic performance of a permanent magnet synchronous machine depends on the properties and topology of the materials used in the manufacture of the rotor $[1,2,5]$.

A variety of permanent magnet rotor designs are known. The greatest advantages in terms of obtaining the best performance of the electric motor are possessed by the collector magnetic system of the rotor. Its efficiency is higher than that of a magnetic system with a radial magnetic flux.

The main advantage of the collector design of the rotor magnetic system is the maximum use of the energy of the magnets. The collector design allows for a higher magnetic flux density in the air gap than in a radial magnetic system $[3,4]$.
Thus, a $15 \mathrm{~kW}$ motor was calculated and the following result was obtained. The torque was $180 \mathrm{Nm}$.

The task is to achieve more torque due to topological optimization of the rotor of a synchronous motor.

\section{Initial data}

For optimization, the engine was selected 11 DVM (valve engine), hereinafter referred to as the "engine".

The engine refers to general-purpose products, both continuous and cyclic, non-repairable. The engine is designed to work with a special semiconductor converter (electric drive)

This machine has the following characteristics:

- shaft rotation frequency of $750 \mathrm{rpm}$;

- voltage in the DC link of the electric drive $520 \mathrm{~V}$;

- without rotor position sensor, climatic modification B2;

- rated power $15 \mathrm{~kW}$;

- long-term permissible motor current at a moment of load on the shaft - $40 \mathrm{~A}$;

-lonely permissible moment of load on the shaft at a speed of $100 \mathrm{Nm}$;

- operating ambient temperature from minus 60 to plus 50;

- relative humidity of the environment of $80 \%$ at a temperature of plus 27;

- degree of protection of the IP55 engine.

According to the number of permissible operable states, engines belong to products of type 1, which during operation can be either in an operable state (state

\footnotetext{
*Corresponding author: sarkazan@bk.ru
} 
with nominal efficiency) or in an inoperable state (state of failure) [7].

Depending on the application mode, the engines belong to equipment operating in continuous use mode and the main part of the operating time is in operation mode $[8,9]$.

We have chosen this engine, since it is a rather simple design for topological optimization, and already based on the algorithm for our PMSM we will develop a universal optimization program.

To check the optimization, we will use the ELCUT program. ELCUT is a modern program for engineering modelling of electromagnetic, thermal and mechanical problems by the finite element method, which is suitable for calculating torque. ELCUT contains a magnetostatics module that can be used to calculate and analyse devices such as a solenoid, electric machines, magnetic screens, permanent magnets, magnetic disks, and the like.

\section{Calculation algorithm}

The following topological optimization algorithm is proposed (using the example of a permanent magnet synchronous motor with an internal rotor, the stator design and stator current are assumed to be given).

The design area of the rotor, which is a cross section (the problem is axisymmetric), is divided into a network of cells - finite elements with a material inherent in each cell (for example, air, steel, varieties of magnets with different directions of magnetization, which are designated $0,1,2,3,4,5$, etc.) $[10,11]$.

Each topology is coded with a unique code. Based on the genetic algorithm, the search for the best solution is carried out. The two initial samples are randomly selected. Several cells are then selected for exchange by homogeneous crossing and as a result two new samples are created $[12,20]$.

The new samples inherit the best characteristics of the previous samples, then the process is repeated. The samples are evaluated by the highest value of the objective function, which is the result of calculating the electromagnetic moment $[13,21,22]$.

In order to speed up processor computations, a multithreaded (with threads independent of each other) approach is used (the program reserves from 1 to 16 threads depending on the processor idle time) $[14,18,19]$.

A procedure for cleaning materials is proposed to obtain homogeneous structures in the projected area (for example, without air pockets in magnets), which makes it possible to simplify the manufacture of a prototype $[15,16,17]$.

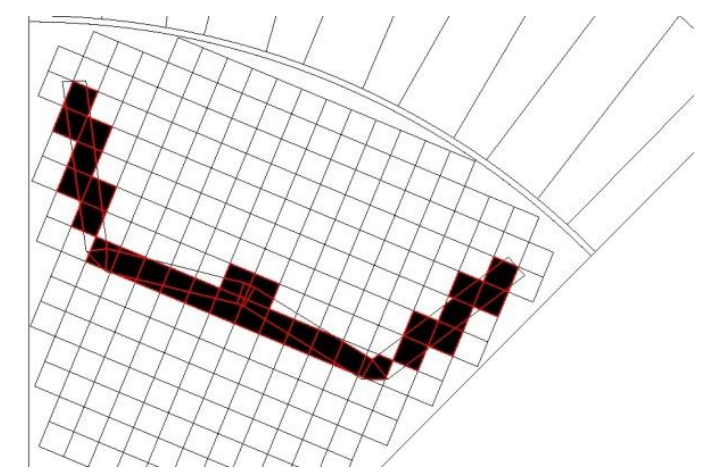

Fig. 1. Calculated version of the rotor topology.

When carrying out topological optimization (based on a genetic algorithm) and changing the rotor design (practically realizable), we got that the shape of the magnets should take the form $\mathrm{W}$ or $\mathrm{V}$. For the first implementation, we chose the option with the form $\mathrm{W}$ (the calculated version of the rotor topology is shown in Figure 1).

Thus, this synchronous motor was calculated and the following result was obtained (the magnetic induction in the motor is shown in Figure 2). The torque was 220 $\mathrm{Nm}$, thus, the increase in torque occurred by $18.2 \%$, which indicates the prospects of topological optimization for permanent magnet synchronous motors.

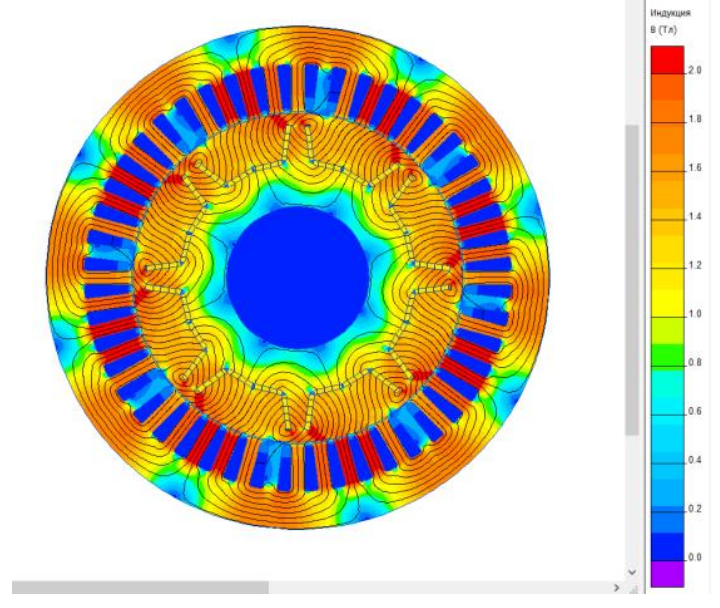

Fig. 2. Magnetic induction in the motor.

\section{Conclusion}

A modern method of designing and optimizing rotors of permanent magnet synchronous motors (PMSM) through the use of genetic algorithms is proposed. The operation of synchronous machines instead of asynchronous sucker rod pumping units for electric drives will make it possible to obtain higher energy efficiency parameters.

The proposed method makes it possible to transfer topological optimization to electromagnetic processes in the PMSM to determine the location and direction of the magnetization of permanent magnets in the rotor for a given mass and dimensional parameters. 


\section{Acknowledgements}

The reported study was funded by RFBR, project number 18-48-160023.

\section{References}

[1] B.E. Vasiliev, L.A. Magerramova, Analysis of the possibility of using topological optimization in the design of uncooled turbine blades, Vestnik SGAU, 3-1 (2015)

[2] C. Li, I.Y. Kim, Multi-material topology optimization for automotive design problems, Proceedings of the Institution of Mechanical Engineers, Part D: Journal of Automobile Engineering 232, 14, 1950-1969 (2018)

[3] E.I. Gracheva, O.V. Fedorov, Forecasting Reliability Electrotechnical Complexes of In-Plant Electric Power Supply Taking into Account LowVoltage Electrical Apparatuses, International Conference on Industrial Engineering, Applications and Manufacturing (ICIEAM), Sochi, Russia, 1-5 (2019)

[4] K.A. Bashin, R.A. Torsunov, S.V. Semenov, Methods of topological optimization of structures used in the aerospace industry, Bulletin of the PNRPU, Aerospace engineering 4, 51 (2017)

[5] K.L. Shenoy, M.S. Kumar, Design topology and electromagnetic field analysis of Permanent Magnet Brushless DC motor for electric scooter application, International Conference on Electrical, Electronics, and Optimization Techniques, ICEEOT 2016, 1541-1545 (2016)

[6] T.I. Petrov, A.R. Safin, I.V. Ivshin, A.N. Tsvetkov and V.Y. Kornilov, The Prospects of Using a Synchronous Machine with Permanent Magnets in the Oil Industry, 2018 14th International ScientificTechnical Conference on Actual Problems of Electronic Instrument Engineering, APEIE 2018 Proceedings, 8546157, 336-338 (2018)

[7] H. Shim, S. Wang, K. Hameyer, Topology optimization of magneto thermal systems considering eddy current as Joule heat, IEEE Trans. Magn. 43, 4, 1617-1620 (2007)

[8] D.N. Dyck, D.A. Lowther, Automated design of magnetic devices by optimizing material distribution, IEEE Trans. Magn. 32, 3, 1188-1193 (1996)

[9] S. Wang, D. Youn, H. Moon, J. Kang, Topology optimization of electromagnetic systems considering magnetization direction, IEEE Trans. Magn. 41, 5, 1808-1811 (2005)

[10] A. Safin, A. Kopylov, R. Gibadullin, T. Petrov, R. Khusnutdinov, O. Fedorov, Thermal Model of a Linear Electric Machine, 1st International Conference on Control Systems, Mathematical Modelling, Automation and Energy Efficiency (SUMMA), Lipetsk, Russia, 426-428 (2019)
[11] D.H. Kim, J.K. Sykulski, D.A. Lowther, The implications of the use of composite material in electromagnetic device topology and shape optimization, IEEE Trans. Magn. 45, 3, 1154-1157 (2009)

[12] J. Lee, N. Kikuchi, Structural topology optimization of electrical machinery to maximize stiffness with body force distribution, IEEE Trans. Magn. 46, 10, 3790-3794 (2010)

[13] E.I. Gracheva, O.V. Naumov, A.N. Gorlov, Modelling Characteristics of Reliability LowVoltage Switching Devices on the Basis of Random Checks on the Example of Contactors, Proceedings - 2019 1st International Conference on Control Systems, Mathematical Modelling, Automation and Energy Efficiency, SUMMA 2019, 8947595, 641643 (2019)

[14] J.S. Choi, J. Yoo, Structural topology optimization of magnetic actuators using Genetic algorithms and ON/OFF sensitivity, IEEE Trans. Magn. 45, 5, 2276-2279 (2009)

[15] L.L. Myagkov, S.M. Sivachev, E.E. Strizhov, S.P. Chirsky, Topological optimization of a highperformance diesel piston, Dvigatelestroyeniye, 2, 3-10 (2018)

[16] C.T. Krasopoulos, I.P. Armouti, A.G. Kladasn, Hybrid Multiobjective Optimization Algorithm for PM Motor Design, IEEE Transactions on Magnetics 53, 745 (2017)

[17] K.L. Shenoy, M.S. Kumar, Design topology and electromagnetic field analysis of Permanent Magnet Brushless DC motor for electric scooter application, International Conference on Electrical, Electronics, and Optimization Techniques, ICEEOT, 1541 (2016)

[18] C.H. Im, H.K. Jun, Y.J. Kim, Hybrid genetic algorithm for electromagnetic topology optimization, IEEE Transactions on Magnetics 39, 2163 (2003)

[19] J.S. Choi, J. Yoo, Structural topology optimization of magnetic actuators using Genetic algorithms and ON/OFF sensitivity, IEEE Transactions on Magnetics 45, 2276 (2009)

[20] J. Lee, N. Kikuchi, Structural topology optimization of electrical machinery to maximize stiffness with body force distribution, IEEE Transactions on Magnetics 46, 3790 (2010)

[21] D.H. Kim, J.K. Sykulski, D.A. Lowther, The implications of the use of composite material in electromagnetic device topology and shape optimization, IEEE Transactions on Magnetics 45, 1154 (2009)

[22] T. Labbe, B. Dehez, Convexity-oriented mapping method for the topology optimization of electromagnetic devices composed of iron and coils, IEEE Transactions on Magnetics 46, 1177 (2010) 